\title{
Original and Simple Protocol for Withdrawal of Benzodiazepines to Achieve Sustained Remission
}

\author{
Granato Philippe ${ }^{1}$, Vinekar Shreekumar ${ }^{2}$, Fontaine Audrey ${ }^{1}$, Paradis Philippe ${ }^{3}$, \\ Danel Thierry ${ }^{4}$, Cottencin Olivier ${ }^{5,6}$ \\ ${ }^{1}$ Pôle de Psychiatrie, Centre Psychothérapeutique de Maubeuge, Centre Hospitalier Sambre Avesnois (CHSA), \\ Maubeuge, France \\ ${ }^{2}$ Department of Psychiatry and Behavioral Sciences, College of Medicine, University of Oklahoma, \\ Oklahoma City, OK, USA \\ ${ }^{3}$ Pôle de Santé Publique de Maubeuge, Centre Hospitalier Sambre Avesnois (CHSA), Maubeuge, France \\ ${ }^{4}$ Fédération Régionale de Recherche en Santé Mentale (F2RSM), Lille, France \\ ${ }^{5}$ Psychiatry and Addiction Medicine Department, CHU-Lille, Lille, France \\ ${ }^{6}$ SCALab, PsyCHIC Team, CNRS UMR 9193, University of Lille, Lille, France \\ Email: "philippe.granato@gmail.com
}

Received 25 February 2016; accepted 26 April 2016; published 29 April 2016

Copyright (C) 2016 by authors and Scientific Research Publishing Inc.

This work is licensed under the Creative Commons Attribution International License (CC BY).

http://creativecommons.org/licenses/by/4.0/

\section{(c) (i) Open Access}

\begin{abstract}
Benzodiazepines are psychotropic medications for effective management of anxiety. However, after over 50 years of unrestrained prescription use, prescribers realize the severity of side effects in select patients. The most challenging of these side effects is the emergence of a physiological dependence that explains virtual impossibility of successful withdrawal that can ensure sustained abstinence. We propose a method for successful withdrawal using substitution and innovative downward tapering of diazepam oral solution for all benzodiazepines to attain sustained remission. Our protocol reported here allowed not only successful withdrawal for all of 20 patients included in this pilot study but also helped in totally weaning them off of benzodiazepines demonstrating absence of relapse even 2 years after the total discontinuance.
\end{abstract}

\section{Keywords}

Benzodiazepine, Withdrawal, Success

${ }^{*}$ Corresponding author. 


\section{Introduction}

In the early 1970's, the dangerousness of barbiturates and search for safer drugs resulted in physicians mostly choosing to prescribe benzodiazepines (BZDs) for anxiety. Throughout the last 50 years, BZDs have become the most prescribed drugs in the world as a first line of treatment for anxiety (13). In fact, $12 \%$ to $16 \%$ of adults in developed countries are taking BZDs consistently. (15). USD \$134 million worth of BZDs were sold in 2010. France had one of the highest rates of hypnotic and anxiolytic drug consumption in Europe (AFSSAPS), (ANSM), [1]-[3].

In addition, the consumption of BZDs tends to soar with age: Lagnaoui et al. [4] showed that, regardless of gender, prevalence of BZD use increased from 30\% between the ages of 51 and 70 years to over $55 \%$ in population over the age of 70 years.

However, the prima facie safety of BZDs that is at the root of the BZD popularity in the 70's has turned out to be an illusion. The BZD molecule, whose efficacy is nowadays discussed as beneficial in the treatment of anxiety, as it can be, also is associated with major concerning side effects that have turned this overused drug into a substantial public health risk [5]. Initially intended as temporary or short term prescriptions of BZD tend to last longer than they are intended for, and gradually become more permanent on the patient's medication profile, usually at the subtle or not so subtle urging by the patients themselves. This is coupled with the sincere desire to help seen among the doctors in resolving the problem of anxiety. Such decision for long term use of BZD to relieve anxiety indeed turns out to be a quick and dirty solution for the wide-spread anxiety related syndromes [6]. The continuous consumption of BZD indeed has a strong potential for habituation that results in undesirable unintended physical/psychological dependency in addition to well intended and acceptable therapeutic dependency. It is a common knowledge that nowadays $1 / 3$ of women over $50,1 / 5$ of men over 50 , [6]-[9] and $14 \%$ of the non-institutionalized over 60 population uses medically prescribed BZDs on an uninterrupted basis [4] [10]. Yet, more the population grows in age, the more side effects can be observed: falls with or without fractures, memory impairment, confusion, attention deficits that may lead to accidental injuries to patients, etc., [8] [11]. By inducing long term cognitive deficits, BZDs also contribute to precipitating emergence of acquired no-reversible major neurocognitive disorders that mimic Alzheimer's disease [12]-[14] and in emerging cases these disorders are clinically indistinguishable from Dementia of the Alzheimer's type.

All these arguments underline the utmost importance of judicious discontinuance and cessation of BZD use whenever clinically justifiable. However, considerable impediments arise when it comes to withdrawal: the usual impediments are absence or infrequency of demand for such measure initiated by the patients, the frequent, rapid, and even consistently repeated relapses according to some authors even after successful withdrawal, and the regrettably ubiquitous BZD withdrawal syndrome (BZDWS) of varied severity which is most dreaded by the patients. Difficulties faced during withdrawal process mostly depend on the length of treatment, dosages [15] and the withdrawing protocol used as well as the unwillingness of the patients. Numerous strategies have been studied, and their efficiency is limited, especially in the outpatient settings. Indeed, the rapidly graduated decrease of dosage recommended by current protocols is to be used during hospitalization in controlled environments, to minimize the hospital stays and as a rule it is almost impossible to achieve successful implementation of such protocols in outpatient clinics [16]. There is a general consensus that withdrawal discomfort could be eased by the simultaneous use of Selective Serotonin Reuptake Inhibitor [17] [18]. In these cases, even though relapse rate is lowered, the severity of BZDWS remains the same [17] [18]. Some authors also suggest that we combine gradual cessation of BZDs combined with Cognitive Behavior Therapy and/or 12 Step-Program proposed by AA (Alcoholics Anonymous).

Even considering the heterogeneity of recommend protocols, presenting difficulties in implementing them in outpatient clinics, [3] [19] [20], the obvious benefits of these protocols outweigh the risks and inconvenience of withdrawal. Among such benefits the most desirable is the significant decline in psychiatric morbidity 6 months [21] after successful discontinuance. We have been thinking of a protocol that could be used in our daily practice that could offer not only this benefit but also a total remission from BZD dependence. In this paper we would like to share a clinical experience of BZD withdrawal undertaken by following a simple empirical protocol that can have tremendous public health impact.

\section{Material \& Methods}

\subsection{Sample}

This study took place in a health service nursing home "Maison d’Accueil Spécialisée” in Denain in North re- 
gion of France. The experience begins in April 2013 and ends in September 2013.

All participants were under guardianship. We explained to guardians the benefits and purpose of BZD withdrawal: better alertness, fewer side effects, etc. They all accepted the value of such effort and consented to withdrawal and discontinuance of BZDs. Out of a total of 42 only 20 patients treated with BZD were selected. The inclusion criteria were informed consent by guardians and willingness of the healthy participants. Patients suffering from chronic pain and other serious chronic ailments were excluded from the study.

We also communicated with the nurses who prepare and administer medications, the details and the usefulness of this approach. In addition we organized many meetings in order to inform nurse's aids (Mental Health Technicians-MHTs) and paramedics. They all understood the ins and outs of this study, the utmost importance of their role and the fact that, in the long haul, fewer users of BZDs would mean lower amount of work for care-givers.

We put together a sample of 20 patients (10 men, 10 women, mean age: $48.4 \pm 11.3$ ) with known severe predominantly genetically transmitted psychiatric disorders namely subjects with significant intellectual disability, psychotic disorders, and pervasive developmental disorder, as defined by DSM-IV. It is acknowledged here that the diagnosis of pervasive developmental disorder is officially deleted from DSM V but was commonly used during the time this clinical trial was conducted.

The severity of the psychopathologies had led to long term care (13 years \pm 7 years) in an institution that would be described as long term residential care facility (Nursing Home).

Patients were well known to the attending physicians and caregivers. There was no turn-over and it was a steady long term population. Medication administration and the actual consumption of medications were systematically checked by nurses and were tallied as well as cross-checked.

Characteristics of patients are summarized in Table 1. Patients were taking BZDs for 27 years $\pm 5-6$ years. Over time, behavioral symptoms, self-mutilation, increased aggression and combativeness towards others, agitation, sleep disorders, etc. were all used as legitimized indications for BZD prescriptions and the fear of resurgence of these symptoms seemed to be the reason for sustained long term use of BZD prescriptions. Thus, in order to maintain the initial effect, it progressively became necessary to increase dosage, because of the phenomenon of tolerance. Many previous withdrawal attempts failed due to high dependency on BZDs, patients becoming decompensated and the resultant institutional imbalance or sometimes stormy disruption of milieu as an immediate consequence of BZD discontinuance.

\subsection{Protocol}

This proposed protocol was inspired by the work of Professor Heather Ashton (http://www.benzo.org.uk/freman/bzcha01.htm). We used the same protocol as reported by Zitman \& Couvec [18] based on the correspondence or equivalence between targeted BZD and $10 \mathrm{mg}$ diazepam tablets (http://www.benzo.org.uk/freman/bzcha01.htm). The originality of our idea is that we transformed the diazepam tablets in drops of diazepam oral solution. We converted the tablet form dosage of every BZD of every patient into solution form, following the equivalence: $10 \mathrm{mg}$ of diazepam tablet $=30$ drops of oral solution of diazepam for oral administration. However, some BZDs were already prescribed in solution or liquid form at the beginning of our study. We calculated the equivalence to a hydrate form of other specific BZDs, and then used the same previous rule or methodology of gradual reduction of dosage utilizing diazepam oral solution. We substituted diazepam oral solution for the original BZD in every patient.

For example, 0.5 milligrams (mg) of alprazolam (Xanax) is approximately equivalent to $10 \mathrm{mg}$ of diazepam (Valium) (http://www.benzo.org.uk/manual/bzcha01.htm). And $1 \mathrm{ml}$ contains 30 drops, corresponding to $10 \mathrm{mg}$ of diazepam (http://www.onmeda.fr/medicament/valium-roche-93111303.html).

https://dailymed.nlm.nih.gov/dailymed/index.cfm.

Daily scheduled administration of dosage of the diazepam oral solution was identical to that of the a hydrate BZD.

Each week, we reduced only 2 drops at each scheduled dose of the day (Figure 1). Volumes of oral diazepam solution for weekly use were stored in small plastic containers closed with a waterproof lid. A picture of the patient was stuck on the external side of the container including his/her identification by name and date of birth to be verified at administration of each dose.

The preparation of 20 containers required specific attention by the pharmacists and the nurses. Weekly changes in the 20 dosage schedules were a major and difficult challenge of this approach. Each patient had an 
Table 1. Characteristics of patients who benefited from the withdrawal.

\begin{tabular}{|c|c|c|c|c|c|c|c|c|c|c|}
\hline & & $\begin{array}{c}\mathrm{M}=\text { male } \\
\mathrm{F}=\text { femelle }\end{array}$ & $\begin{array}{l}\text { Diagnosis: } \\
\text { Severe } \\
\text { Intellectual } \\
\text { disability }\end{array}$ & Treatment & Age & $\begin{array}{l}\text { former } \\
\text { treatment }\end{array}$ & dosages & $\begin{array}{c}\text { DIAZEP } \\
\text { AM } \\
\text { equivalent }\end{array}$ & $\begin{array}{c}\text { Withdrawal } \\
\text { Duration in } \\
\text { weeks }\end{array}$ & $\begin{array}{c}\text { Cost } \\
\text { per } \\
\text { year }\end{array}$ \\
\hline 1 & $\mathrm{BB}$ & M & idiopathic & $\mathrm{AD}+\mathrm{TR}+\mathrm{BZD}$ & 50 & $\begin{array}{l}\text { Alprazolam } \\
0.25 \mathrm{mg}\end{array}$ & $1-1-1$ & $15-15-15$ & 8 & 65 \\
\hline 2 & $\mathrm{BL}$ & $\mathrm{F}$ & idiopathic & $\begin{array}{c}\mathrm{TR}+\mathrm{AE}+\mathrm{ED}+\mathrm{AP} \\
+\mathrm{BZD}\end{array}$ & 40 & $\begin{array}{l}\text { Diazepam } \\
10 \mathrm{mg}\end{array}$ & $0-0-1$ & $0-0-30$ & 15 & 25 \\
\hline 3 & $\mathrm{DE}$ & M & idiopathic & $A D+A P+B Z D$ & 25 & $\begin{array}{l}\text { Prazepam } \\
10 \mathrm{mg}\end{array}$ & $1-0-1$ & $20-0-30$ & 15 & 30 \\
\hline 4 & $\mathrm{DP}$ & $\mathrm{F}$ & idiopathic & $\begin{array}{c}\mathrm{AD}+\mathrm{AE}+\mathrm{AP}+ \\
\mathrm{BZD}\end{array}$ & 53 & $\begin{array}{l}\text { Oxazepam } \\
10 \mathrm{mg}\end{array}$ & $1-0-1$ & $15-15-15$ & 8 & 25 \\
\hline 5 & $\mathrm{DR}$ & M & $\begin{array}{l}\text { Tuberous } \\
\text { sclerosis }\end{array}$ & $\begin{array}{c}\mathrm{AD}+\mathrm{TR}+\mathrm{AE}+ \\
\mathrm{AP}+\mathrm{BZD}\end{array}$ & 23 & $\begin{array}{l}\text { Clorazepat } \\
10 \mathrm{mg} \\
\text { Clorazepat } \\
20 \mathrm{mg}\end{array}$ & $\begin{array}{l}0-1-0 \\
1-0-1\end{array}$ & $40-20-40$ & 20 & $\begin{array}{c}48 \\
152\end{array}$ \\
\hline 6 & NJC & $\mathrm{F}$ & $\begin{array}{l}\text { malformation } \\
\text { syndrome }\end{array}$ & $\mathrm{AE}+\mathrm{AP}$ & 55 & $\begin{array}{l}\text { Prazepam } \\
10 \mathrm{mg}\end{array}$ & $0-0-1$ & $0-0-30$ & 15 & 47 \\
\hline 7 & $\mathrm{PM}$ & F & idiopathic & $\mathrm{AD}+\mathrm{AP}$ & 61 & $\begin{array}{c}\text { Alprazolam } \\
0.25 \mathrm{mg}\end{array}$ & $0-0-1$ & $0-0-15$ & 8 & 18 \\
\hline 8 & $\mathrm{RD}$ & M & idiopathic & $A D+B Z D$ & 41 & $\begin{array}{c}\text { Alprazolam } \\
0.25 \mathrm{mg}\end{array}$ & $1-1-1$ & $15-15-15$ & 8 & 65 \\
\hline 9 & WD & M & Autism & $\mathrm{AE}+\mathrm{AP}+\mathrm{BZD}$ & 42 & $\begin{array}{l}\text { Prazepam } \\
10 \mathrm{mg}\end{array}$ & $0-0-1$ & $0-0-30$ & 15 & 42 \\
\hline 10 & $\mathrm{BM}$ & F & Trisomy 21 & BZD & 60 & $\begin{array}{c}\text { Clobazepam } \\
5 \mathrm{mg}\end{array}$ & $0-0-1$ & $0-0-8$ & 4 & 22 \\
\hline 11 & BR & F & $\begin{array}{l}\text { very serious } \\
\text { psychosis }\end{array}$ & $A D+A P+B Z D$ & 49 & $\begin{array}{l}\text { Oxazepam } \\
10 \mathrm{mg}\end{array}$ & $1-0-1$ & 15-0--15 & 8 & 38 \\
\hline 12 & DJP & F & Autism & $\mathrm{AD}+\mathrm{AP}+\mathrm{BZD}$ & 61 & $\begin{array}{l}\text { Oxazepam } \\
10 \mathrm{mg}\end{array}$ & $2-0-2$ & $30-0-30$ & 15 & 141 \\
\hline 13 & EMN & M & $\begin{array}{l}\text { Synd. } \\
\text { Polymalforma } \\
\text {-tions }\end{array}$ & $\mathrm{AE}+\mathrm{BZD}$ & 37 & $\begin{array}{l}\text { Oxazepam } \\
10 \mathrm{mg}\end{array}$ & $2-0-2$ & $30-0-30-$ & 15 & 125 \\
\hline 14 & GA & M & idiopathic & $\mathrm{AD}+\mathrm{AP}+\mathrm{BZD}$ & 61 & $\begin{array}{l}\text { Zolpidem } \\
10 \mathrm{mg}\end{array}$ & $0-0-1$ & $0-0-15$ & 8 & 66 \\
\hline 15 & VS & $\mathrm{F}$ & Autism & $\mathrm{AE}+\mathrm{BZD}$ & 53 & $\begin{array}{l}\text { Zolpidem } \\
10 \mathrm{mg}\end{array}$ & $0-0-1$ & $0-0-15$ & 8 & 31 \\
\hline 16 & $\mathrm{BC}$ & $\mathrm{F}$ & idiopathic & $\mathrm{AD}+\mathrm{BZD}$ & 45 & $\begin{array}{l}\text { Zolpidem } \\
10 \mathrm{mg}\end{array}$ & $0-0-1$ & $0-0-15$ & 8 & 66 \\
\hline 17 & $\mathrm{CN}$ & M & idiopathic & $\mathrm{AE}+\mathrm{AD}+\mathrm{BZD}$ & 48 & $\begin{array}{l}\text { Oxazepam } \\
10 \mathrm{mg}\end{array}$ & $1-1-1$ & $15-15-15$ & 8 & 140 \\
\hline 18 & $\mathrm{LN}$ & M & Kernicterus & $\begin{array}{c}\mathrm{AD}+\mathrm{AP}+\mathrm{TR}+ \\
\mathrm{BZD}\end{array}$ & 47 & $\begin{array}{l}\text { Alprazolam } \\
0.25 \mathrm{mg}\end{array}$ & $2-2-2$ & $30-30-30$ & 15 & 120 \\
\hline 19 & $\mathrm{VM}$ & $\mathrm{F}$ & $\begin{array}{l}\text { Irradiation in } \\
\text { utero }\end{array}$ & $A D+B Z D$ & 57 & $\begin{array}{l}\text { Alprazolam } \\
0.25 \mathrm{mg}\end{array}$ & $0-0-1 / 2$ & $0-0-8$ & 4 & 17 \\
\hline 20 & VJR & M & idiopathic & $A D+A P+B Z D$ & 60 & $\begin{array}{l}\text { Oxazepam } \\
10 \mathrm{mg}\end{array}$ & $1-1-1$ & $15-15-15$ & 8 & 140 \\
\hline
\end{tabular}

AD: antidepressants, AE: antiepileptic, PA: antipsychotics, BZD: Benzodiazepines, TR: thymus-regulators.

individualized calendar for his medication administration record for every week and the withdrawal protocol was running for months.

\section{Results}

This protocol goes on for several months as against the rapid withdrawal schedules used in acute care settings. 


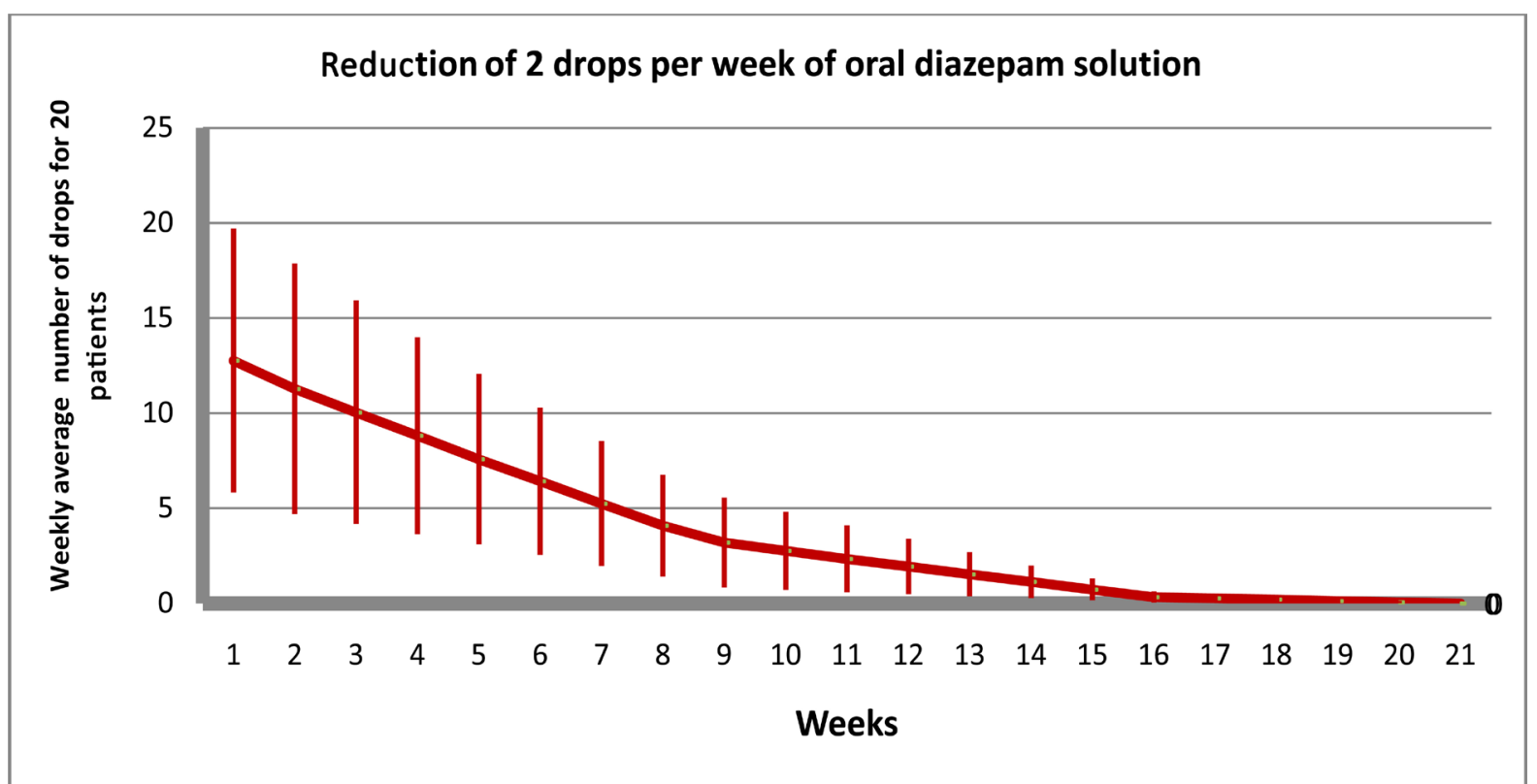

Figure 1. Decrease of 2 drops per week of oral DIAZEPAM solution; profile for 20 residents.

Withdrawal schedules were individualized. What is of note is that there was no emergence of symptoms that constituted the usual BZDWS such as: withdrawal discomfort or uneasiness, tremor, nausea, constipation, difficulties in urination, headaches, musculo-skeletal aches and pains, muscle weakness, massive rebound anxiety, agitation, irritability, nightmares, anorexia, diarrhea, diaphoresis, sweating, mood changes, depression, depersonalization, disorientation, hallucinations, paranoid psychosis, hypersensitivity to noise lights and odors, numbness, tingling, dysgeusia, hyperthermia and rhabdomyolysis, [22] nor any life-threatening condition, such as severe confusion or delirium [22] non-epileptic withdrawal seizures, or aggravation of pre-existing seizure disorder and this, despite the small prevalence of co-morbid epilepsy in this population.

Moreover, after 2 years, no relapses have been detected. Increase in cognitive competencies couldn't be measured nor evaluated due to the original severity of intellectual disability. Nonetheless, patients showed no worsening of their behavioral disorder [10] after the total and complete discontinuance.

Caregivers also reported a lower incidence of daytime drowsiness in patients. They could all participate more easily in daily activities, had higher muscle tone, and could walk more steadily.

Patients were also able to ambulate more independently, according to caregivers. Unfortunately, no standard neurological examination to assess motor strength was serially performed to objectively evaluate the improvement in muscle strength, gait or steadiness.

\section{Discussion}

Our protocol was effective. We were pleasantly surprised to notice that even though some BZDs had very short half-life, no BZDWS was observed in the case of short half-life BZDs. Indeed, it is widely known that more shorter are half-life, more severe are the BZDWS [22]. This makes us confident that our protocol is highly efficient in controlling the emergence of BZDWS.

However, a few limitations of this study have to be emphasized. First, the small size of the sample makes generalization of these results impossible. Moreover, the experimental group in this study comprised of institutionalized long term patients, and consequently necessarily compliant in controlled environment, whereas, outpatients, who would be our wider public health-wise target population, would have been harder to convince to follow a prescription where come down regimen of the dosage varies weekly. Thus, a study based on only highly motivated outpatients would be beneficial or worth undertaking to verify if the results of this study can be replicated in outpatient population. Another point is that our study was not randomized double blind study. We did not use control subjects in this pilot study. Considering the lack of consensus, our goal was limited to empirically come up with a protocol that could be handily used in daily practice in helping highly motivated patients; and 
we were hoping that this clinical experience in real life verified anecdotally by many practitioners may lead the path to further experimental clinical research trials to prove the efficacy of this protocol.

The strength of our work lies in the initial stability of patient population, the absolute certainty of therapeutic compliance, and the involvement and motivation of caregivers. Thus, this protocol cannot be used alone, it has to be complemented with psycho-educational meetings with caregivers and patients to explain the predicted outcomes, by winning the total trust of the motivated patients, and a concerted effort by all the parties involved including the patients' guardians. People in the nursing homes have a similar profile as our population as regards the compliance plan and benefits to stop their BZD medications. Therefore, this study could further guide clinical research trials in gero-psychiatric residential care settings (nursing homes) provided the patients and guardians willingly participate without undue anxiety. Human subject protection considerations should be in favor of such studies if IRBs (Institutional Review Boards) were to note that the benefits far outweigh the risks afforded to experimental subject populations. Simply keeping statistical track of falls, injuries from falls, other accidents, pre and post cognitive assessments, accidental overdose episodes, etc, before starting such studies with similar quantification six months, one year, two year after this study will provide useful data to help popularize this protocol. "Granato-Vinekarprotocol". Naming this protocol will help uniformity of communication in future clinical trials. The originality and possibility of extrapolation orgeneralization in withdrawing other addictive medicationsis likely to encourage future research to replicate our findings.

The economic benefit of such protocol has a potential of staggering proportion. This successful withdrawal enabled a saving of minimum USD \$1500 yearly, that is to say a mean cost saving of USD \$ 75 per patient per year even considering use of cheaper generic formulations.

From this pilot study, we understand that the widespread use of this approach could be profitable for a country, not only from the economic point of view, but also from the global public health point of view, since it enhances patient's quality of life, and reduces in the long run the amount of work for caregivers. This cost saving does not include the indirect savings, especially for senior health care costs entailed in diagnoses and treatment of fractures caused by falls, cases of delirium, and preventable hospitalizations for medical and psychiatric complications related to widespread BZD use, etc.

\section{Conclusions}

Indiscriminate BZD prescribing habits of physicians can be compared to antibiotics prescriptions. In both instances, we have to wait many decades to notice harmful consequences of large and unrestrained use of prescriptions. We now have to cope up with the consequences. Habituation and addiction potential of BZDs being the main issue, our daily challenge as physicians is to help our patients manage to kick the habit of taking BZDs. The model proposed in this paper for a "come down schedule" or "downward titration" can be implemented in our highly motivated out-patients who are currently under treatment. This is where our withdrawal method can make a difference. Its success is based not only on the use of liquid form instead of an a hydrate tablet forms, but also on the diligence and involvement of nurses and support staff. To go further, equivalences between any of the BZDs and oral solution of diazepam, and individualization of prescriptions can be facilitated by the creation of a software program, accessible on-line only for doctors and pharmacists' use in the institutions. This program will dictate "prescription calendar for every patient" and help reduce medication dosage errors and save time needed for monitoring prescriptions. A smartphone application will carefully follow the weekly variations of dosage prescribed by the doctor. We propose the following website www.benzodiazepine-withdrawal.com.

A complementary way to handle the BZD overuse issue is for us prescribing physician to be extremely cautious when prescribing these drugs: to base our thoughts on their action on precise target symptoms, to predetermine with each patient the length of treatment, to always use the minimal dosage, and to avoid mechanically written prescriptions (in auto-pilot rapid speed mode of practice). The high risk of dependency linked to BZD legitimizes strict supervision, and is actually everyone's business/concern. This is the rationale behind the mandated prescription monitoring programs (PMP) adopted by many states in the United States.

Our paper demonstrates that the subjects can be totally and permanently withdrawn from BZDs with no craving for BZDs or necessity for other substitute central nervous system depressants (hypnotic-sedatives) in long term care facilities. The remission from BZD dependence is total remission and can last for good. This finding must be emphasized in addition to the side benefits of reducing energy and effort expended by the care-givers, 
lowering the risk of potentially dangerous side effects of BZDs, and of course, finally the cost to the society in paying for expensive BZDs year after year for the BZD dependent individuals.

This pioneering work is empirical, but we observed no relapse in 2 years after successful discontinuance, granting no one had access to BZDs in controlled environment. The methodology is simple but significant in overcoming cravings for BZDs. However, more scientific studies are needed to confirm or refute the findings of this clinical trial. BZD dependence is a public health problem as much as the abuse of numerous other natural or synthetic drugs of abuse. The weaning is extremely difficult in the treatment of chemical dependency. Also, confirmation of the success of this method starting with BZDs can be extended to all of these drugs of abuse as well as extrapolated to tapering down of corticosteroids and other therapeutic agents presenting the problem of difficult weaning.

Last but not the least, this protocol can also be used for all other addictive medication molecules presenting challenge to successful withdrawal and discontinuation to attain sustained total remission.

\section{Acknowledgements}

We thank all the nursing and administrative staff of the "Maison d'Accueil Spécialisée" of Denain north of France for their involvement and volunteerism in this work. Moreover, we thank " $L$ 'Association de Formation Médicale Continue des Praticiens de l'Hopital de Maubeuge" for the grant to this publication of this work. Also, the authors thank Kelly Kyler, Staff Editor, in the Office for Scientific Research, University of Oklahoma College of Medicine

\section{References}

[1] AFSSAPS (2012)

http://www.ansm.sante.fr/var/ansm_site/storage/original/application/3f1dc4756b5bc091879c9c254d95e05c.pdf

[2] ANSM (2013)

http://ansm.sante.fr/S-informer/Points-d-information-Points-d-information/Etat-des-lieux-en-2013-de-la-consommation -des-benzodiazepines-en-France-Point-d-Information

[3] Baillargeon, L., Landreville, P., Verreault, R., Beauchemin, J.P., Grégoire, J.P. and Morin, C.M. (2003) Discontinuation of Benzodiazepines among Older Insomniac Adults Treated with Cognitive-Behavioural Therapy Combined with Gradual Tapering: A Randomized Trial. Canadian Medical Association Journal, 169, 1015-1020.

[4] Lagnaoui, R., Depont, F., Fourrier, A., Abouelfath, A., Bégaud, B. and Verdoux, H. (2004) Patterns and Correlates of Benzodiazepine Use in the French General Population. European Journal of Clinical Pharmacology, 60, 523-529. http://dx.doi.org/10.1007/s00228-004-0808-2

[5] Darker, C.D., Sweeney, B.P., Barry, J.M., Farrell, M.F. and Donnelly-Swift, E. (2015) Psychosocial Interventions for Benzodiazepine Harmful Use, Abuse or Dependence. Cochrane Database Systematic Reviews, 11. http://dx.doi.org/10.1002/14651858.CD009652.pub2

[6] Fourrier, A., Letenneur, L., Dartigues, J.F., Moore, N. and Bégaud, B. (2001) Benzodiazepine Use in an Elderly Community-Dwelling Population. Characteristics of Users and Factors Associated with Subsequent Use. European Journal of Clinical Pharmacology, 57, 419-425. http://dx.doi.org/10.1007/s002280100326

[7] Briot, M. (2006) Assemblée nationale, Office Parlementaire d’Evaluation des Politiques de Santé (OPEPS), Rapport sur le bon usage des médicaments psychotropes. Assemblée Nationale, Paris.

[8] Lechevallier, N., Fourrier, A. and Berr, C. (2003) Utilisation de benzodiazépines chez le sujet âgé: Données de la cohorte EVA. Revue Epidémiologie Santé Publique, 51, 317-326.

[9] Paterniti, S., Bisserbe, J.C. and Alpérovitch, A. (1988) Médicaments psychotropes, anxiété et dépression dans une population âgée. Etude EVA. Revue Epidémiologie Santé Publique, 46, 253-262.

[10] Authier, N., Balayssac, D., Sautereau, M., Zangarelli, A., Courty, P., Somogyi, A.A., Vennat, B., Llorca, P.M. and Eschalier, A. (2009) Benzodiazepine Dependence: Focus on Withdrawal Syndrome. Annals of Pharmacology, 67, 408413. http://dx.doi.org/10.1016/j.pharma.2009.07.001

[11] Woolcott, J.C., Richardson, K.J., Wiens, M.O., Patel, B., Marin, J., Khan, K.M. and Marra, C.A. (2009) Meta-Analysis of the Impact of 9 Medication Classes on Falls in Elderly Persons. Archive Internal Medicine, 169, 1952-1960. http://dx.doi.org/10.1001/archinternmed.2009.357

[12] Pialot, V. (2014) Benzodiazepines, Risk Factors for Alzheimer Disease. Soins Psychiatriques, 295, 5.

[13] Rickels, K., Schweizer, E., Case, G. and Greenblatt, D.J. (1990) Long-Term Therapeutic Use of Benzodiazepines. Ef- 
fects of Abrupt Discontinuation. Archives of General Psychiatry, 47, 899-907. http://dx.doi.org/10.1001/archpsyc.1990.01810220015002

[14] Zhang, Y., Zhou, X.H., Meranus, D.H., Wang, L. and Kukull, W.A. (2015) Benzodiazepine Use and Cognitive Decline in Elderly with Normal Cognition. Alzheimer Disease Association Disorder, in press. http://dx.doi.org/10.1097/wad.0000000000000099

[15] Lader, M. and Petursson, H. (1983) Rational Use of Anxiolytic/Sedative Drugs. Drugs, 25, 514-528. http://dx.doi.org/10.2165/00003495-198325050-00004

[16] Petrovic, M., Pevernagie, D., Mariman, A., Van Maele, G. and Afschrift, M. (2002) Fast Withdrawal from Benzodiazepines in Geriatric Inpatients: A Randomized Double-Blind, Placebo-Controlled Trial. European Journal of Clinical Pharmacology, 57, 759-764.

[17] Nakao, M., Takeuchi, T., Nomura, K., Teramoto, T. and Yano, E. (2006) Clinical Application of Paroxetine for Tapering Benzodiazepine Use in Non-Major-Depressive Outpatients Visiting an Internal Medicine Clinic. Psychiatry Clinic Neurosciences, 60, 605-610. http://dx.doi.org/10.1111/j.1440-1819.2006.01565.x

[18] Zitman, F.G. and Couvée, J.E. (2001) Chronic Benzodiazepine Use in General Practice Patients with Depression: An Evaluation of Controlled Treatment and Taper-Off. British Journal of Psychiatry, 178, 317-324. http://dx.doi.org/10.1192/bjp.178.4.317

[19] Morin, C.M., Bastien, C., Guay, B., Radouco-Thomas, M., Leblanc, J. and Vallières, A. (2004) Randomized Clinical Trial of Supervised Tapering and Cognitive Behavior Therapy to Facilitate Benzodiazepine Discontinuation in Older Adults with Chronic Insomnia. American Journal of Psychiatry, 161, 332-342. http://dx.doi.org/10.1176/appi.ajp.161.2.332

[20] Oude-Voshaar, R.C., Couvée, J.E., van Balkom, A.J., Mulder, P.G. and Zitman, F.G. (2006) Strategies for Discon- tinuing Long-Term Benzodiazepine Use: Meta-Analysis. British Journal of Psychiatry, 189, 213-220. http://dx.doi.org/10.1192/bjp.189.3.213

[21] Bashir, K., King, M. and Ashworth, M. (1994) Controlled Evaluation of Brief Intervention by General Practitioners to Reduce Chronic Use of Benzodiazepines. British Journal General Practice, 44, 408-412.

[22] Wolf, B. and Griffiths, R.R. (1991) Physical Dependence on Benzodiazepines: Differences within the Class. Drugs and Alcohol Dependence, 29, 153-156. http://dx.doi.org/10.1016/0376-8716(91)90044-Y 